\title{
Use of Remote Sensing Techniques in Hydrology to Mapping Water (Case study: Algadarif Area).
}

\author{
Mustafa Ismael ${ }^{1}$, Faisal Ismail ${ }^{1}$, Mohammed Ahmed ${ }^{1}$, Salah Salih $^{1}$, and Mohmed Abdalhi ${ }^{1}$ \\ ${ }^{1}$ Al-Neelain University
}

May 29, 2021

\begin{abstract}
This study was conducted at Algadarif State Area, east of the Sudan latitudes 12? 17/, longitudes 34? 36/ E, which aimed to build a database of the morphometric of 26 properties from a 176 basin, this done through analyzing a digital elevation model ( DEM ) by using a group of geographical data systems programs, which integrated to result in a large number of morphometric variances and measurements. They are represented in the programs ArcMap 10.4.1 as basic programs and other supportive programs like excel. The study was done for the purpose to understand its hydrologic significances and consequently understanding the water movement on the surface of the base. The study depended on the data of the digital elevation model accurately $30 \mathrm{~m}$ in addition to a group of maps and satellite images. Adoption of Algadarif State upon automatic agriculture who leads to needing to know a lot about conditions, nature and description runoff water for the rain to know the different characteristics for basins to draw the water map of the State, recognition of cadastral characteristics and formal properties, identify the histological properties and water drainage network characteristics. Arc gis was installed on a windows 10 computer and loaded the digital elevation model for the experiment site from earth explorer, the DEM file was only used. Work was done by Arc Hydro Tools within the Arc GIS.
\end{abstract}

\section{Hosted file}

scientific paper.pdf available at https://authorea.com/users/416563/articles/524060-use-ofremote-sensing-techniques-in-hydrology-to-mapping-water-case-study-algadarif-area

\section{Hosted file}

figures.pdf available at https://authorea.com/users/416563/articles/524060-use-of-remotesensing-techniques-in-hydrology-to-mapping-water-case-study-algadarif-area 
RESULTS \& DATABSE OF WATER MAP ALQADARIF

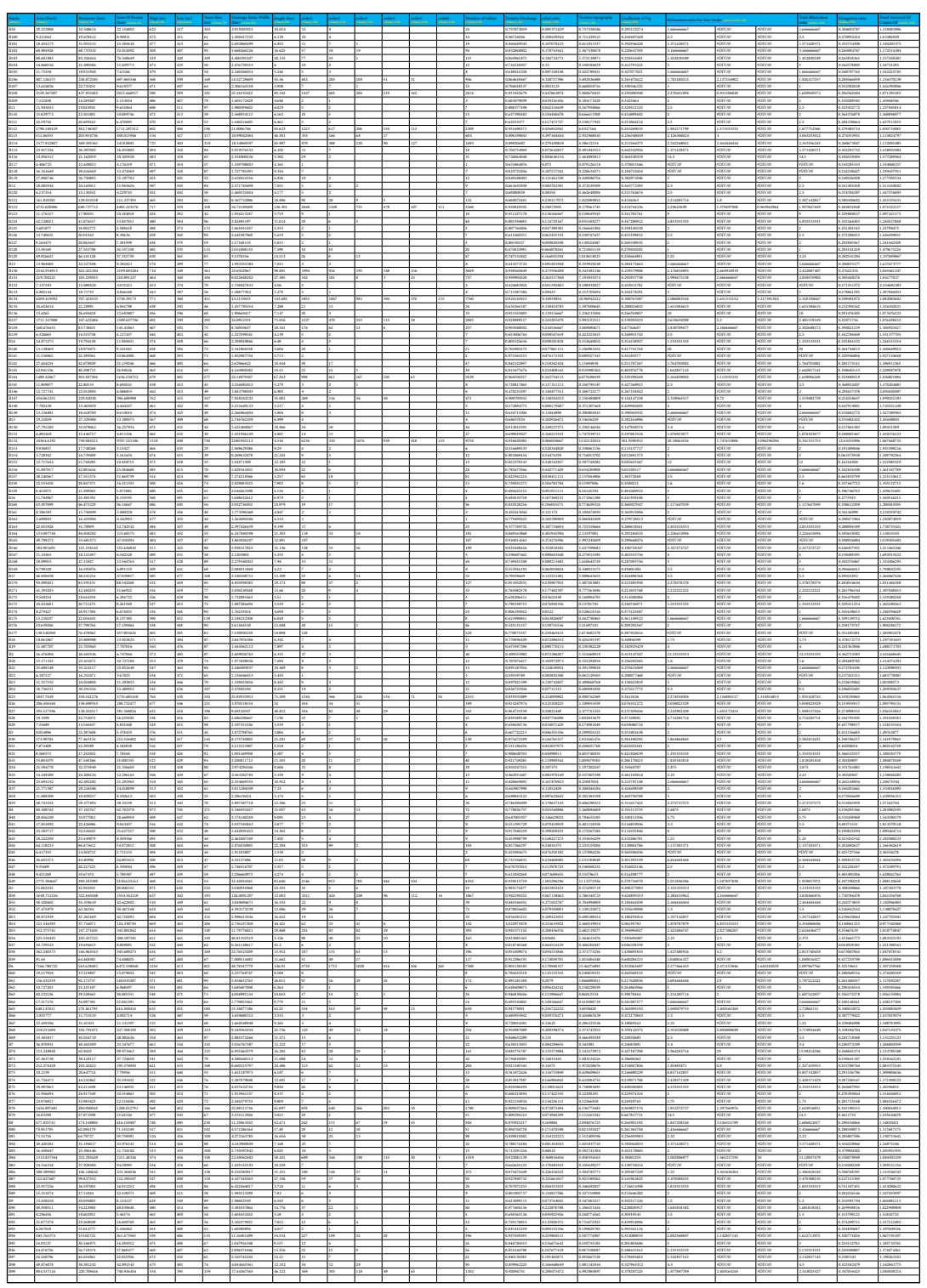

